Memorias del VII Encuentro Nacional de Experiencias en la Enseñanza de la Biología y la Educación Ambiental y II Congreso Nacional de Investigación en la Enseñanza de la Biología

\title{
LA EXPERIENCIA DE VIVIR LA VIDA DESDE LA PARTICIPACIÓN EN LA ENSEÑANZA DE LA BIOLOGÍA
}

\section{THE EXPERIENCE OF LIVING LIFE FROM PARTICIPATION IN THE TEACHING OF BIOLOGY}

\section{Sindy Carolina Buitrago Cuervo ${ }^{1}$ Álvaro Javier Fernández Castro ${ }^{2}$}

\section{Resumen}

El presente trabajo parte de una revisión documental con la cual se pretende confrontar diferentes autores en relación a los conceptos de lo vivo y la vida, en donde surge el mundo de la vida como aquella experiencia de vivir en el mundo. Se cuestiona el pensamiento científico y su relevancia en el quehacer educativo, pues este nos presenta un conocimiento ajeno a los sujetos que viven en la vida cotidiana.

Se hace una invitación a los maestros y maestras al reconocimiento de las subjetividades en donde los niños, niñas y jóvenes son interlocutores válidos en la construcción del sentido de mundo viviente desde la participación.

Palabras clave: Mundo de la vida, participación, subjetividad, enseñanza de la Biología.

\section{Abstract}

This paper begins with a literature review which aims to confront different authors in relation to the concepts of the alive and life, where the world of life comes as the experience of living in the world. At issue is scientific thinking and its relevance to educational work, as this gives us a knowledge foreign to subjects living in everyday life.

It is an invitation to teachers to recognition of subjectivities where children and youth are valid partners in building the sense of the world of life from participation.

1 Licenciada en Biología de la Universidad Pedagógica Nacional. Integrante de la línea de investigación Ciencia, Acciones y Creencias - DBI-UPN. E-mail: angakilla@hotmail.com

2 Licenciado en Biología de la Universidad Pedagógica Nacional. Integrante de la línea de investigación Ciencia, Acciones y Creencias - DBI-UPN. E-mail ajfcbog@gmail.com 
Edición Extra-Ordinaria. ISSN 2027-1034 P. p 614-621

Memorias del VII Encuentro Nacional de Experiencias en la Enseñanza de la

Biología y la Educación Ambiental y II Congreso Nacional de Investigación en la Enseñanza de la Biología

Keywords: World of life, participation, subjectivity, teaching biology.

\section{Introducción}

El conocimiento moderno se constituye hoy como algo exterior al humano, no conmueve en lo íntimo, es la forma dominante de relacionarnos con el mundo, homogenizando las experiencias, que no son experiencias propias, son obtenidas a través de los medios masivos, atraviesan a los sujetos pero no los transforma. La experiencia es el vivir en un mundo de afección; "la experiencia no es lo que pasa, es lo que nos pasa" (Larrosa, 2003). La experiencia es el caminar, el trasegar en el sentir, el vivir la vida.

Lo vivo, encerrado en el pensamiento científico tiene características particulares que no tienen en cuenta la experiencia, que sólo es experiencia en la especie humana, el mundo de la vida.

\section{El mundo de la vida}

Mayr (2005) presenta la dicotomía que existe al hablar de la vida y el proceso de vivir, dado a que el primero no se puede llevar a una comprobación científica en relación con el segundo que sí la puede alcanzar y es bajo está última que se determina lo vivo como un conjunto de programas evolucionados, con propiedades químicas, con mecanismos de regulación, organizados, como sistemas de magnitud limitado y un ciclo vital, agregando a ello la cualidad de sistemas alejados del equilibrio térmico.

Como es bien sabido por todos, estos parámetros de lo vivo son el resultado de un sin número de investigaciones y debates dentro de la comunidad especializada, comunidad que se basa de un método unificado, unión de ideas en donde se establece un objeto- no un sujeto en términos humanos- desde principios epistemológicos y reglas metodológicas, que lo único que nos llevan a alcanzar, es el alejamiento, la división del ser con su ser, el desconocimiento propio y de un alejamiento del mundo, es decir, la experiencia del sujeto se pierde, no es válida en la construcción de mundo, es como lo plantea Gadamer (2006), incontrolable e inestable.

Para aclarar ello, se hace necesario recordar que según Gadamer (2006) a los resultados del trabajo científico se les denomina "ciencia" y a lo referido a la experiencia se le denomina práctica. La diferencia trascendental radica en la comprobación de sus hechos, la objetividad y subjetividad desde el método científico van por caminos incomparables. 
Edición Extra-Ordinaria. ISSN 2027-1034 P. p 614-621

Memorias del VII Encuentro Nacional de Experiencias en la Enseñanza de la

Biología y la Educación Ambiental y II Congreso Nacional de Investigación en la

Enseñanza de la Biología

(...) condenar el pensar a la objetividad vacía, tiene como resultado la predación del mundo de la vida, asunto que tendrá como consecuencia más próxima, que la razón que es mucho más extensa que el entendimiento humano, quede reducida al actuar técnico-instrumental poniendo de manifiesto, según Husserl, que los hombres y el mundo sean interpretados como cosas, como datos que conforman un hecho regularizado según los criterios de la ley de causa-efecto (Delgado \& Prada, 2008, pág. 43)

Es pertinente en este momento cuestionarnos sí es posible pensar en una real y legítima objetividad por parte de la ciencia moderna. ¿Quiénes, bajo dichas prácticas, se encuentran regidos por unas experiencias propias y contextuales? ¿Es posible que el sujeto se desligue de su experiencia y logre pensar en una objetividad ajena a su ser? Es necesario recordar que aunque los sujetos se expongan al "mismo" fenómeno los sujetos desde su individualidad, desde su ser social y cultural responderán a él de manera diferente, ya sea de manera tangible o intangible, ello es lo que hace que en el sujeto sea sublime. (Delgado \& Prada, 2008, pág. 44)

En base a ello se hace un llamado a la fenomenología ya que en y desde ella, se permitiría pensar en la esencia de las vivencias y no sólo se reduciría el proceso de vivir -desde la biología- a los procesos fisiológicos, anatómicos, ecológicos, ambientales, evolutivos, etc., sino que además de estos, se podrá tener en cuenta la experiencia, el mundo de la vida.

Por lo que definir la vida

[s]ólo desde el nivel molecular, no tiene ningún sentido, no puede darse a la vida una definición únicamente física, únicamente biológica, únicamente elemental, únicamente totalizante, únicamente organizacional, únicamente existencial. Toda definición de vida que privilegia a un único término rigidifica y mutila (...) la vida no se reducirá nunca a una fórmula sino que nunca la aprehenderemos como tal, puesto que el acto mismo de percibirla es ya una manifestación de ella... ni siquiera podemos concebir todas las potencialidades, puesto que estas se revelan a través del tiempo, y nos devoran en el pasado y en el futuro (Vargas. 2001, pág.241)

El mundo de la vida, como se le ha denominado a la aventura de pensar en lo vivido a cada instante por los sujetos, requiere como su nombre lo indica, de un mundo, de un espacio, de un reconocimiento, que facilite que dichas prácticas se signifiquen y se constituyan en y desde los implicados, es por ello, que se debería dejar de pensar en la disociación del mundo y objetos ajenos a nuestro ser, el 
Edición Extra-Ordinaria. ISSN 2027-1034 P.p 614-621

Memorias del VII Encuentro Nacional de Experiencias en la Enseñanza de la

Biología y la Educación Ambiental y II Congreso Nacional de Investigación en La

Enseñanza de la Biología

mundo es parte de cada ser que lo habita y lo reconstituye. Un mundo de significado se constituye y constituye a quienes lo significan. Desconocer el mundo y sus dinámicas, es desconocer la naturaleza de los sujetos. La enemistad con el mundo, es negar posibilidades de ser, se debe combatir la objetivación; el alejamiento, para posibilitar experiencias de amistad-acercamiento- (Delgado \& Prada, 2008)

\section{La enseñanza de la Biología desde las intersubjetividades}

Jorge Larrosa (2003), nos dice que en la sociedad moderna, los seres humanos somos espectadores que buscan un goze intrascendente e instantáneo, al mostrarnos como consumidores de información, de noticias, arte, literatura, etc; mientras permanecemos exteriores, ajenos e impasibles. El conocimiento en la actualidad es algo exterior a nosotros, como una mercancía. "Estamos informados, pero nada nos con-mueve en lo íntimo". Sobre lo que también señala Marta Nussbaum (2011) que el modelo educativo dominante ha dado más importancia al "liderazgo" y con él sus tests que evidencian que el centro en el aprendizaje es el conocimiento aplicado, ya que esto favorece las estrategias de la obtención de renta, que no (necesariamente) involucran la investigación científica.

Mientras tanto, en el quehacer educativo, no aplica estrictamente la investigación científica como ejes metodológico y conceptual fundamentales. No obstante, vemos que la investigación en la escuela pierde relevancia al no encontrar un paradigma que sustente su validez en la cotidianidad de los actores educativos.

Entendiendo al maestro como un sujeto investigador, se encuentra este en la cotidianidad entre diferentes paradigmas que remiten a múltiples sentidos y significados al no tener un asidero propio, arraigado en el contexto particular, pues generalmente se traen modelos teóricos y metodológicos foráneos que se espera sustenten una investigación, que de entrada está marcada con el rechazo a la diferencia cultural, política y social. Además, el paradigma, tal como lo presenta Thomas Kuhn, son las "realizaciones científicas universalmente reconocidas que, durante cierto tiempo, proporcionan modelos de problemas y soluciones a una comunidad científica" (Kuhn, 2004). Entonces, en la práctica, estas realizaciones científicas constituyen una visión de mundo restringida que orienta la práctica educativa a través de las creencias y actitudes del investigador y su grupo o escuela de científicos.

Por lo tanto, consideramos que el conocimiento objetivo, ajeno a nosotros, tal como se pretende trabajar en los procesos educativos formales, pierde validez en tanto se deja de lado lo subjetivo y lo diferente y se centra en el desarrollo de un paradigma desarrollado por científicos naturales. No sería contrario a esto pensar que el alejar la subjetividad del pensamiento que se enseña en la escuela, "limita y reduce nuestra capacidad de formación y transformación” (Larrosa, 2003, pp.18), 
Edición Extra-Ordinaria. ISSN 2027-1034 P. p 614-621

Memorias del VII Encuentro Nacional de Experiencias en la Enseñanza de la

Biología y la Educación Ambiental y II Congreso Nacional de Investigación en la Enseñanza de la Biología

tal como Larrosa señala que ocurre con la lectura encerrada en el ámbito trivializado de lo imaginario.

En este sentido, debemos posicionar lo subjetivo, la imaginación, que lejos de ser

irrealidad, ficción, delirio, fantasía, alucinación, sueño, etc... es una facultad mediadora entre lo sensible y lo inteligible, entre la forma y el intelecto, entre lo objetivo y lo subjetivo, entre lo corporal y lo incorporal, entre lo exterior y lo interior... La imaginación, como el lenguaje, produce realidad, la incrementa y la transforma (Larrosa, 2003 pp. 17).

Consideramos entonces, que se debe posibilitar una educación dialógica, desde la cual se aleje el monólogo de la escuela y se propenda por un diálogo de sujetos y sociedades, desde el cual se fomenten relaciones sensibles, de amistad, de añoranza y reconocimiento por iniciativas propias y conjuntas desde el despliegue de las intersubjetividades. Debemos propender por una educación dialógica, pues es parte de la naturaleza del ser humano dialogar a través de la palabra, ligada a la acción y a la reflexión.

Para la especie humana el mundo de la vida o mundo de significado, no debe explicarse únicamente teniendo en cuenta la relación causa-efecto, como ya es pensado en tiempos modernos, debemos reconocer que los sujetos se transforman en su cotidianidad presente y desde unos preceptos históricos que los constituyen, razón que requiere pensar en la vida como significado, atravesada por las emociones y los deseos, usualmente execrados por el pensamiento científico, pero que en la realidad le dan sentido a las acciones cotidianas en nuestras familias, escuelas, organizaciones, sociedades y el mundo natural, argumento que debemos tener como central cuando comprendemos que "la educación tiene que ver con las personas que participan en tales procesos" (Dávila y Maturana, 2009). Somos seres que viven en el lenguaje, comprender nuestra existencia es la fuente de nuestra libertad, pues

[e]xplicamos nuestra experiencia con las coherencias de nuestra experiencia, y al hacerlo cambia nuestra experiencia... Es en esa libertad que esta comprensión educativa queda configurada como una invitación a ver que todo el vivir humano ocurre como tal en las relaciones humanas en la continua creación de mundos, ya sea en la ciencia, la técnica, la filosofía, el arte, o en el simple convivir. En verdad, ese es el tema de nuestra aproximación a la ciencia en el proyecto educativo propuesto: el vivir, y desde la comprensión del vivir $y$ del convivir, ver que la realidad pertenece al explicar del vivir $y$ el convivir humano (Dávila y Maturana, 2009). 
Memorias del VII Encuentro Nacional de Experiencias en la Enseñanza de la Biología y la Educación Ambiental y II Congreso Nacional de Investigación en La Enseñanza de la Biología

En este sentido, Dávila y Maturana (2009) proponen el docente de la post posmodernidad, fluido en un convivir reflexivo con niños, niñas y adultos, participe en la creación de espacios de convivencia; que conviva y viva con sus educandos y con los otros y otras, que les permita una transformación en adultos en un convivir democrático, capaces de crear estos espacios de convivencia. Para esto, el maestro debe contar con algo más que el conocimiento específico del área en la que se encierra, pues debe reflexionar y actuar con los niños, niñas y jóvenes, en autonomía reflexiva y el respeto siempre por los otros y las otras.

Si un educando convive con un profesor de biología y este profesor disfruta su biologizar en el respeto y atención a las dificultades que en algún momento puedan tener sus alumnos, ese educando incorporará de manera espontánea en su vivir la mirada biológica, y la biología será el instrumento de convivencia a través del cual se va a transformar en un adulto socialmente integrado, con confianza en sí mismo, con capacidad de colaborar y aprender cualquier cosa sin perder su consciencia social, y por lo tanto ética (Dávila y Maturana, 2009).

\section{La participación en la vida cotidiana}

Este podría ser el profesor de biología que proponga la construcción de espacios democráticos que posibiliten el "ser, hacer y querer hacer parte de un espacio vivencial" de encuentro con el otro y la otra, encontrarse como iguales sin ocultar las diferencias, siendo esta la esencia de la participación (Estrada, et. al. 2011), vista esta como:

un proceso individual, grupal, colectivo y comunicativo de construcción de lo público, encaminado a la posibilidad y capacidad de intervenir en la toma de decisiones sobre lo común, desde la comprensión, el encuentro y la diversidad para compartir, crear, soñar y desear mundos posibles (Estrada, et. al. 2011).

En este sentido, si pensamos en los niños, niñas y jóvenes como interlocutores válidos, capaces de tomar decisiones y actuar de acuerdo a sus intenciones y gustos propios, debemos encontrar un lugar de confluencia de intersubjetividades, en donde se logre el encuentro con el otro y con la otra, con esa participación que constituya sujetos democráticos. Este lugar que no es físico, pero que se posibilita en el encuentro en escenarios físicos, es descrito por Berger y Luckman (1997) como aquello que compartimos con los demás, a lo cual denominan como la vida cotidiana. Estos autores señalan que en este espacio es donde se dan las relaciones e interacciones con el mundo, con los otros y las otras a través del cara a cara, el aquí y el ahora. La vida cotidiana es "inherente a todas y todos, por su 
Memorias del VII Encuentro Nacional de Experiencias en la Enseñanza de la Biología y la Educación Ambiental y II Congreso Nacional de Investigación en La

\section{Enseñanza de la Biología}

misma permanencia, es invisible a nuestros ojos" (Castañeda, et. al., 2010), debido a que la vida cotidiana se esconde detrás de los problemas y retos diarios, detrás del pasado y el futuro.

Cabe señalar que la vida cotidiana está constituida por: reglas y normas, hábitos y rutinas, gustos y creencias, recuerdos y memoria, interacciones sociales, etc, que se relacionan directamente con la cultura (Berger y Luckman, 1997).

En este sentido, podemos pensarnos una enseñanza de la biología que busque espacios democráticos, en donde podamos biologizar desde las diferentes expresiones artísticas y culturales que, como lenguajes, posibilitan la relación dialógica entre los estudiantes con los maestros, con las familias y con su comunidad desde las diferentes experiencias que confluyen.

\section{Conclusiones}

El conocimiento científico no debe ser el pilar central en la enseñanza de las ciencias, en la actualidad se requiere de la confluencia de saberes locales, experienciales y culturales para lograr legítimos espacios de participación con el otro y la otra. Para lo cual, se requiere propiciar escenarios de diálogo donde el maestro propicie una reflexión desde su accionar en escenarios de acercamiento y reconocimiento de la diferencia en la construcción de mundo.

La enseñanza de la biología desde el escenario de la convivencia con el mundo posibilita la participación en el reconocimiento del otro: niño, niña, jóvenes,adultos, planta, animal, microorganismo, hongos, mundo, etc., permitiendo entender la biología desde las relaciones.

La imaginación posibilita la creación y la transformación. no se debe trivializar, pues es un atributo fundamental en la construcción de mundo, sea de manera científica o no; además de permitirnos darle sentido a la vida.

\section{Bibliografía}

- Berger, P; y Luckmann T. 1991. La construcción social de la realidad. Amorrortu editores: Buenos Aires.

- Castañeda, E. 2010. Dos formas de contar y tejer la experiencia: Sistematización proyecto Re-creo 2009-2010. Convenio por la primera infancia y la inclusión. IDIE de Primera Infancia y Derechos de la Niñez - OEI-; Subdirección para la infancia Secretaría Distrital de Integración Social -SDIS- Alcaldía Mayor de Bogotá. 
Edición Extra-Ordinaria. ISSN 2027-1034 P.p 614-621

Memorias del VII Encuentro Nacional de Experiencias en la Enseñanza de la Biología y la Educación Ambiental y II Congreso Nacional de Investigación en la

\section{Enseñanza de la Biología}

- Dávila, X; Maturana, H. 2009. Hacia una era post posmoderna en las comunidades educativas. Revista Iberoamericana de educación, núm 49: Enero Abril 2009. Tomado en línea el: 12 de Julio de 2013, en: http://www.rieoei.org/rie49.htm

- Delgado, C. A., \&Prada, M. A. (2008). Mundo de la vida, lenguaje,ciencia y tecnología: esbozos de una critica a la razón científico instrumental. Teoría y Praxis Investigativa, 3 (2).

- Estrada, M; et.al. 2011. El arte camino para la participación. Una aproximación desde lo dramático y lo sonoro. Alcaldía Mayor de Bogotá: Secretaría de Integración social.

- Gadamer, H. -G. (2006). Estética y hermenéutica. España: Tecnos.

- Kuhn, T. 1986. La estructura de las revoluciones científicas. Fondo de cultura económica: México.

- Larrosa, J. 2003. La experiencia de la lectura: Estudios sobre literatura y formación. Fondo de cultura económica: México D.F.

- Mayr, E. 2005. Así es la Biología. Ed. Debate: Madrid

- Nussbaum, M. 2011. La crisis silenciosa. Revista Signo y pensamiento, vol. XXX, núm. 58, enero-junio, 2011, pp. 16-22, Pontificia Universidad Javeriana: Bogotá.

- Vargas, O. 2001. La noción de vida en la biología contemporánea. En: Colombia Revista Javeriana ed: v.557 fasc. p.93 - 103,1989 